JP3I (Jurnal Pengukuran Psikologi dan Pendidikan Indonesia), I0(I), 202I, 20-3I

D0l: http://dx.doi.org/I0.15408/jp3i.v10il.I72I6

http://journal.uinjkt.ac.id/index.php/jp3i

\title{
Development and Validation of Ethical Awareness Scale among University Students
}

\author{
Retno Kumolohadi ${ }^{1}$, Frieda Mangunsong ${ }^{2}$, Julia Suleeman ${ }^{3}$ \\ Faculty of Psychology and Faculty of Social Science, Universitas Islam Indonesia, Indonesia ${ }^{1}$ \\ Faculty of Psychology, Universitas Indonesia, Indonesia ${ }^{1,2,3}$ \\ retno.kumolohadi@ui.ac.id
}

\begin{abstract}
Plagiarism, intolerance, and sexual harassment highlight the assessment of university students' ethical awareness as essential measure. The study aims to develop and validate an ethical awareness scale by constructing a measuring instrument based on Yeung and Keup's (2009) preliminary research, using open ended questionnaire and focus group discussions, expert judgement, and legibility test. 251 students were recruited through convenience sampling. The results of psychometric testing using exploratory factor analysis indicate that the 12 -item scale is valid in terms of construct validity. The Kaiser Meyer Olkin test showed a score of 0.865 , with a Bartlett' s Sphericity test value of $1.240, \mathrm{df}=66$ and $\mathrm{p}=0.000$, and the factor loading ranged from 0.409 to 0.814 . Total variance explained by this scale is $46.827 \%$, in which academic and social factors contribute to $39.001 \%$ of variance, while information technology contributes to $7.826 \%$ of variance. Reliability testing using Cronbach's Alpha yielded a coefficient value of $\alpha=0.874$. The implications of this study include the necessities for further development of the instrument to specifically measure information technology factor, to conduct confirmatory factor analysis with other students, and to modify the scale based on participants' different characteristics. This scale can also be used to determine the effectiveness of ethics outreach programs.
\end{abstract}

Keywords: scale validation, ethical awareness, exploratory factor analysis, item analysis, reliability. 


\section{Introduction}

Ethical awareness refers to a sensitivity to recognize moral and ethical issues in certain situations, and to compare them to the standard norms of society (Rest, Narvaez, Thoma, \& Bebeau, 2000). Donaldson and Dunfee (2017) explained that the norms adopted by a society can take the form of universal values rooted in philosophy, social life, and religious doctrines, as well as local norms based on the fundamental principles of a specific community. How does an individual come to possess ethical awareness? Treviño, den Nieuwenboer, and Kish-Gephart (2014) claimed that ethical awareness occurs when an individual has the accurate knowledge of various ethical issues, which provides the individual with a schema of such ethical issues in their mind used to identify whether or not something is considered ethical. Furthermore, according to Martinov-Bennie and Mladenovic (2015), ethical awareness needs to also be integrated with an awareness of actions based on the principles of legality and rules, and thoughts about the consequences of actions for the relevant parties.

University students, as part of society with the advantage of access to higher education, should thus possess ethical awareness. Yet, some university students still display behaviors that are considered wrong, inappropriate, or unethical, such as plagiarism, bullying, intolerance, and sexual harassment. It is possible that students still lack the in-depth awareness and comprehension of ethical issues, despite their cognitive development having reached the moral-conventional stage that should be adequate for the comprehension of ethical issues. Beginning at 18 years of age, university students enter adulthood where they broaden their insights, care for others (Hurlock, 2006), and are subject to the norms and rules of society (Rest et al., 2000). This discrepancy between expectations and reality reinforces the importance of measuring instruments to identify levels of ethical awareness and reveal the array of ethical issues that are less understood.

Defining Issues Test (i.e., DIT I and DIT2) and Multidimensional Ethical Scale (MES) are widely used to measure ethical awareness and both instruments fulfill the psychometric criteria of good instruments. Yet, DIT is limited in terms of the relevance between ethical issues and daily practices, in the themes expressed in ethical dilemmas, and in the variation of response options (Shawver \& Sennetti, 2019). On the other hand, the MES constructed by Reidenbach and Robin (Buchan, 2014)has been criticized for its weak ability to reveal concrete behaviors, and respondents have reported difficulties in understanding and differentiating the ethical philosophies related to justice, relativism, egoism, utilitarianism, and deontology that are explicitly expressed in the scale's items.

An instrument intended to be used specifically with university students is one developed by Yeung and Keup (2009) for assessing perception towards personal and peer group ethical values and behaviors, in the context of common ethical themes. The themes are categorized into three dimensions, namely academic, social, as well as campus facilities and information technology dimensions. In Yeung and Keup's study, 1568 university students in the United States participated, and the instrument showed Chronbach's reliability coefficient of $\alpha=0.65$. However, in the social dimension, some items incline towards behavioral indicators specific to western culture, suggesting that the instrument may not be applicable to Indonesian university students. For example, items in the social dimension assess the misuse of identification cards in bars and the usage of campus dining facilities in excess of the acceptable limit. Meanwhile, the two other dimensions (i.e., academic dimension and campus facilities and information technology dimension), are composed of behavioral indicators that are relatively similar to those included in Yeung and Keup's instrument.

A more favorable instrument should include scenarios that reflect reality and correspond to the context of the research (Bairaktarova \& Woodcock, 2017). Individuals can therefore visualize a more concrete situation and be more aware of the possible existence of various influences, including situational factors and personal factors such as motivation for personal gain, expected consequences, and personality. Several existing instruments are directly and specifically associated with ethical standards, but they are not meant for use with university students. These instruments include ethical awareness scales for engineering students 
(Bairaktarova \& Woodcock, 2017), nurses (Milliken, 2017; Milliken, Ludlow, DeSanto-Madeya, \& Grace, 2018), and teachers (Gholami \& Tirri, 2012). Based on explanations above, the purpose of the current study is to develop and validate an ethical awareness scale that addresses ethical issues relevant to university students and to the context of Indonesian culture. Considering the limitations of the existing instruments, the development of a new instrument for ethical awareness assessment is crucial.

\section{Methods}

\section{Procedure}

The following are the procedures of this study, which were adopted from Nguyen (2010). (1) Construction of an instrument consists of (a) literature review for the definition of the construct of the measuring instrument; (b) construction of scale items with cultural adaptation (i.e., through administration of a semi open-ended questionnaire and a focus group discussion with subjects); (c) expert judgment for revision and readability of items; (d) identification and selection of sampling strategy, as well as a report of the demographic characteristics of subjects; (e) discussion of data collection preparation with team of researchers, screening procedures based on statistical analysis, anticipation of missing values in data set, and selection of the right statistical technique for data analysis; (f) data collection.

(2) Test of the psychometric properties of the scale, which was comprised of: (a) Exploratory Factor Analysis (EFA) to evaluate underlying factor structure and modification of items. An EFA is usually followed by a Confirmatory Factor Analysis (CFA) using a separate sample obtained from the same population to evaluate the results obtained from EFA regarding factor structure and the psychometric properties of the measurement. (b) Explanation of the matrix analysis used. This particular study only used Exploratory Factor Analysis.

\section{Construction of Instrument}

The construction of the instrument commenced with a decision on the construct of measurement, which was ethical awareness. An ethical awareness (EA) scale was then developed based on the indicators proposed by Yeung dan Keup (2009) (see Table 1). Further cultural adaptation is essential to ensure that the items of the scale correspond to the context of Indonesian students. To carry out the cultural adaptation procedure, the researchers conducted a pilot study consisted of two phases. In the first phase, the researchers conducted a survey using semi open-ended questionnaire inquiring about ethical themes, feelings, and processes involved when students are facing ethical issues. The second phase was a focus group discussion. Data collection was done by a research team comprised of one main researcher and a research assistant, who was a Master's degree student in Psychology. The research assistant was briefed on the questionnaire to ensure proper comprehension of the content and appropriate administration of informed consent to respondents.

\section{Pilot Study: Exploration of Ethical Awareness Scale Themes}

124 university students responded to the semi open-ended questionnaire in the first phase of the pilot study. The participants involved in this phase were recruited using convenience sampling and were made up of 98 undergraduate students (79\%) and 26 graduate students $(21 \%)$ from one public university and one private university in Yogyakarta. All of the participants were at least 18 years old (mean age $=20.54$ ) and were active students. 120 of the participants were Muslim (97\%), while the remaining participants were non-Muslim. 76 of them were of Javanese descendant (61\%), while the rest of the participants came from various ethnic groups, including Sundanese, Betawi, Madurese, Balinese, Buginese, Batak, Malay, Minangkabau, Sasak, Banjarese, Kutainese, Tobaru, Gorontaloan, Bendang, Oganese, Ternatenese, and Chinese Indonesians. In the second phase, 14 of the university students who had filled the semi open-ended questionnaire and had agreed to participate in the focus group discussion were divided into two groups. 
The focus group discussion was intended to further probe into ethical themes. Subsequently, the indicators that were most commonly experienced by university students were selected and formulated into scale items. The comparison between the indicators from Yeung and Keup (2009) and the indicators obtained from the pilot study is illustrated in Table 1.

Table 1. Comparison of Dimensions and Indicators of Ethical Violations in Students among Yeung and Keup (2009), Pilot Study Data (Questionnaire N=124; Discussion N=14), and Ethical Awareness Scale (N=251)

\begin{tabular}{|c|c|c|}
\hline $\begin{array}{l}\text { Dimensions and Indicators by } \\
\text { Yeung \& Keup (2009) }\end{array}$ & Indicators from pilot study & $\begin{array}{l}\text { Indicators in EA } \\
\text { Scale }\end{array}$ \\
\hline \multicolumn{3}{|l|}{ Academic Dimension } \\
\hline $\begin{array}{l}\text { Plagiarism in completing } \\
\text { assignments }\end{array}$ & Plagiarism in completing assignments & Plagiarism \\
\hline \multirow[t]{4}{*}{ Cheating on a test } & Cheating on a test & Cheating \\
\hline & Being late for class & \\
\hline & $\begin{array}{l}\text { Skipping class while asking a friend to } \\
\text { sign attendance sheet on one's behalf }\end{array}$ & Skipping class \\
\hline & $\begin{array}{l}\text { Falsifying signature in attendance sheet } \\
\text { (class, internship) }\end{array}$ & Signature forgery \\
\hline $\begin{array}{l}\text { Lying to a professor about the } \\
\text { reason for absence }\end{array}$ & $\begin{array}{l}\text { Lying to a professor during } \\
\text { confirmation of attendance signature }\end{array}$ & \\
\hline \multicolumn{3}{|l|}{ Social Dimension } \\
\hline \multirow{8}{*}{$\begin{array}{l}\text { Preventing other students from } \\
\text { doing well }\end{array}$} & Conflicts in friendship, Bullying & \\
\hline & Lying to parents & \\
\hline & Running away from home & \\
\hline & Intimacy beyond acceptable boundaries & Premarital sex \\
\hline & $\begin{array}{l}\text { Falsifying documents during vehicle } \\
\text { registration and licensing }\end{array}$ & \\
\hline & Breaking curfew & \\
\hline & $\begin{array}{l}\text { Traffic violations, Speeding } \\
\text { Stealing }\end{array}$ & Speeding \\
\hline & $\begin{array}{l}\text { Joining group activities to protest } \\
\text { campus policy }\end{array}$ & $\begin{array}{l}\text { Anti-norm } \\
\text { movements }\end{array}$ \\
\hline $\begin{array}{l}\text { Fraud in selling entertainment } \\
\text { tickets for campus activities }\end{array}$ & $\begin{array}{l}\text { Misuse of campus organization finances, } \\
\text { lack of transparency in the conditions } \\
\text { surrounding management of campus } \\
\text { organization (Corruption) }\end{array}$ & Corruption \\
\hline \multicolumn{3}{|l|}{$\begin{array}{l}\text { Misuse of identity card to gain } \\
\text { entry to a bar }\end{array}$} \\
\hline $\begin{array}{l}\text { Cheating when taking food } \\
\text { rations from the campus } \\
\text { cafeteria }\end{array}$ & $\begin{array}{l}\text { Using campus facilities for personal } \\
\text { benefits (Corruption) }\end{array}$ & \\
\hline \multicolumn{3}{|l|}{ Facilities and Information } \\
\hline \multicolumn{3}{|l|}{ Technology Dimension } \\
\hline $\begin{array}{l}\text { Illegal download of copyrighted } \\
\text { material from the internet }\end{array}$ & & $\begin{array}{l}\text { Illegal download of } \\
\text { articles and books }\end{array}$ \\
\hline Illegal installation of software & & Installation of \\
\hline onto personal computer & & unlicensed software \\
\hline Illegal parking in campus area & & Illegal parking \\
\hline Misuse of parking permits & & \\
\hline Ignoring campus cleanliness & & Littering \\
\hline
\end{tabular}

Source: Personal Data (2019) 
Common ethical themes among students were then extracted from the results of the focus group discussion with 14 students. The focus group discussion also managed to expand on the indicators identified in the semi open-ended questionnaire. For instance, students reported that they still take their total percentage of attendance into consideration when skipping class while at the same time taking into account the professor's tolerance and the priority ranks of their other activities. Students also admitted to asking their friends to sign in the attendance sheet on their behalf in their absence. At the same time, some other students claimed to feel reluctant rejecting their absentee friends' request to sign the attendance sheet on their behalf. Discussion with the students also revealed that within the social dimension, the behavior that is most likely to be performed is violating traffic rules. Said traffic rule violations include speeding to violate traffic light when rushing to class. In addition, speeding typically occurs when there is an opportunity to do so, when the roads are empty, and when students feel bad about the possibility of being late to a scheduled appointment. Other social issues that were identified encompass hesitation in refusing friends' objectionable invitations, including invitations to drink alcohol, to engage in premarital sex, and to join extremist group activities.

Findings from the pilot study were used by the researchers to then formulate the components (factors) and indicators, as well as to construct them into statement items. The constructed statements were general and not too specific in nature. Afterwards, the components and indicators of the construct were outlined as a blueprint. In the first part of the scale, participants were informed of the definition of ethical issues, which refers to issues that can be evaluated as either good or bad, positive or negative, appropriate or inappropriate, and issues that result in consequences. The scaling method chosen was a 3-point Likert scale: (a) involving an ethical issue corresponds to a score of 2, (b) possibly involving an ethical issue corresponds to a score of 1 , and (c) not involving an ethical issue corresponds to a score of 0 . The researchers showed the constructed statements to four experts for evaluation and feedback (i.e., professional judgment). The experts were members of one of the authors' dissertation supervisory team, comprising of a promotor and a co-promotor, as well as a university lecturer specializing in Psychometrics and a university lecturer specializing in Social Psychology. Table 2 shows the formulated blueprint.

Table 2. Blueprint of Scale of Ethical Awareness Scale

\begin{tabular}{|c|c|c|c|c|}
\hline $\begin{array}{l}\text { No } \\
\text {. }\end{array}$ & $\begin{array}{l}\text { Dimension } \\
\text { (Factor) }\end{array}$ & Behavioral Indicator & Item Number & $\begin{array}{l}\text { Total } \\
\text { Items }\end{array}$ \\
\hline 1 & Academic & $\begin{array}{l}\text { plagiarism, skipping class, signature forgery, } \\
\text { cheating }\end{array}$ & $1,2,3,4$ & 4 \\
\hline 2 & Social & $\begin{array}{l}\text { speeding, corruption, premarital sex, anti-norm } \\
\text { movements }\end{array}$ & $5,6,7,8$ & 4 \\
\hline \multirow[t]{2}{*}{3} & $\begin{array}{l}\text { Campus facilities } \\
\text { and information } \\
\text { technology }\end{array}$ & $\begin{array}{l}\text { illegal download of articles and books, } \\
\text { installation of unlicensed software, illegal } \\
\text { parking, littering }\end{array}$ & $9,10,11,12$ & 4 \\
\hline & & & Total & 12 \\
\hline
\end{tabular}

Source: Personal Data (2019)

In the next step, the researchers performed a readability test. As many as 20 respondents were asked to test the readability of the scale. The purpose of the test was to obtain feedback about the scale's relevance, the clarity of content, and the effectiveness of the statements included. Some sentences deemed to be too lengthy, wordy, and irrelevant were subsequently revised. The items formulation adhered to the proper and correct Indonesian language's terminology. 


\section{Study to Test Psychometric Properties of Scale}

251 respondents participated in the phase of study in which the psychometric properties of the EA scale were tested. The respondents were selected using a convenience sampling method. 240 (95.62\%) of the respondents were undergraduate students and $11(4.38 \%)$ were graduate students, all of whom were recruited from two universities (i.e., one public university and one private university) in Yogyakarta. 77 of the respondents (30.68\%) majored in Science and Technology (i.e., Faculty of Mathematics and Natural Science; Faculty of Engineering), while 174 of them (69.32\%) majored in the Social and Humanities fields (i.e, Faculty of Law; Faculty of Psychology; Faculty of Economics; Faculty of Cultural Studies). 109 $(43.43 \%)$ of the respondents were males and $142(56.57 \%)$ of the respondents were females, with a mean age of 20.10 .

The constructed scale was then distributed to the participants for them to fill in. The collected data was checked individually, and all respondents completed all of the items in the scale. The exploratory factor analysis in this study was run using SPSS software version 20.

\section{Results and Discussion}

\section{Exploratory Factor Analysis Results}

All scales distributed to 251 university students were completed and returned without any missing data. An Exploratory Factor Analysis is intended to identify the number of factors (dimensions) in a group of scale items used to describe a variable. Exploratory factor analysis (EFA) is also known as common factor analysis/principle axis analysis, and in this research the analysis was done using orthogonal varimax rotation. The purpose of the EFA is to discover the factors that serve as a basis for the construct of the instrument, by taking into account the local sociocultural context, as well as reducing the number of scale items. According to Fabrigar, MacCallum, Wegener, and Strahan (1999), data reduction involves decreasing the number of factors from the variable of origin into a smaller number of factors, while ensuring that the factors are mutually independent, such that the numerous items of the scale can be reduced. Furthermore, Reio and Shuck (2015) suggested that exploratory factor analysis is useful for determining the number of latent variables and finding out the inadequacy of the theory.

Item selection was carried out through item discrimination analysis (item difference test) before conducting the exploratory factor analysis. All items had a corrected item-total correlation of 0.473-0.686 (above the critical limit of 0.3 ). Corrected item-total correlation shows the power of item discrimination. This study only used items with an item discrimination power of 0.30 or more.

In the next step, using exploratory factor analysis, the number of statement items is reduced and extracted to reveal the possibility of a new factor within the variable. EFA allows researchers to obtain new factors that may not exactly match the theory due to differences in context. The factor loading is required to be at least 0.30. In addition, EFA can yield the Kaiser Meyer Olkin (KMO) Measure of Sampling Adequacy value, which reveals sample's adequacy, and the Bartlett test of Sphericity to obtain the significance of the correlation between variables as well as to ensure suitable variables for further processing without any exclusions. The ideal $\mathrm{KMO}$ is $>0.50$ with a significance value of $p<0.05$. The EFA results after Bartlett's KMO test demonstrate the contributions of the factors included in the scale. As seen in Table 3 , the criteria of a good scale are fulfilled. 
Table 3. EFA Results Based on Sampling Adequacy and Factor Contribution (N=251)

\begin{tabular}{llcc}
\hline \multicolumn{1}{c}{ Computation } & Criteria & Results & Annotation \\
\hline KMO measure of sampling adequacy & $>0.5$ & 0.865 & Sample is adequate \\
Bartlett's test of Sphericity & & 1.240 & \\
Df & $<0.05$ & 66 & \\
$\mathrm{p}$ & & 0.000 & Significant \\
\hline
\end{tabular}

Source: Personal Data (2019)

According to Costello and Osborne (2005), an exploratory factor analysis is fit if a clean factor structure is obtained, which is when the item factor loading is above 0.30 , when there is no factor cross-loading, and when there are at least three items per factor. Therefore, in an effort to obtain a clean factor structure, a researcher can manipulate the number of factors, specifically by removing items with a factor loading of lower than 0.30 and those with cross-loading. Based on Yeung and Keup's (2009), ethical awareness scale, semi open-ended questionnaire, and FGD, a total of 12 items were constructed. Following the EFA, the number of items remained unchanged; extracted number of factors $=$ two factors, factor loading $=0.4$ (minimum of 0.3), with a factor loading range of 0.409-0.814 (see Table 4).

All of the items in the ethical awareness scale show engine values factor with a factor loading above 0.4 (i.e., with a minimum of 0.3 ). The factor loading of each item, obtained from EFA with orthogonal varimax, can be seen in Table 4.

Table 4. Factor Loadings from Exploratory Factor Analysis of the Ethical Awareness (EA) Scale

\begin{tabular}{clc}
\hline No & \multicolumn{1}{c}{ Item Statement } & Factor Loading \\
\cline { 2 - 3 } & $\begin{array}{l}\text { Plagiarism is an act that involves/does not involve/possibly involves ethical } \\
\text { consequences }\end{array}$ & 0.592 \\
2 & $\begin{array}{l}\text { Skipping class is an act that involves/does not involve/possibly involves ethical } \\
\text { consequences }\end{array}$ & 0.423 \\
3 & $\begin{array}{l}\text { Signature forgery is an act that involves/does not involve/possibly involves } \\
\text { ethical consequences }\end{array}$ & 0.634 \\
4 & $\begin{array}{l}\text { Cheating is an act that involves/does not involve/possibly involves ethical } \\
\text { consequences }\end{array}$ & 0.591 \\
5 & $\begin{array}{l}\text { Speeding is an act that involves/does not involve/possibly involves ethical } \\
\text { consequences }\end{array}$ & 0.409 \\
6 & $\begin{array}{l}\text { Corruption is an act that involves/does not involve/possibly involves ethical } \\
\text { consequences }\end{array}$ & 0.801 \\
7 & $\begin{array}{l}\text { Premarital sex is an act that involves/does not involve/possibly involves ethical } \\
\text { consequences }\end{array}$ & 0.688 \\
8 & $\begin{array}{l}\text { Anti-norm movement is an act that involves/does not involve/possibly involves } \\
\text { ethical consequences }\end{array}$ & 0.603 \\
9 & $\begin{array}{l}\text { Illegal download of articles and books is an act that involves/does not } \\
\text { involve/possibly involves ethical consequences }\end{array}$ \\
10 & $\begin{array}{l}\text { Installation of unlicensed software is an act that involves/does not } \\
\text { involve/possibly involves ethical consequences }\end{array}$ \\
11 & $\begin{array}{l}\text { Illegal parking is an act that involves/does not involve/possibly involves ethical } \\
\text { consequences }\end{array}$ & 0.814 \\
12 & $\begin{array}{l}\text { Littering is an act that involves/does not involve/possibly involves ethical } \\
\text { consequences }\end{array}$ & 0.511 \\
\hline
\end{tabular}

Source: Personal Data (2019)

Next, dimension 1 (factor 1) was labeled "academic and social" (items 1, 2, 3, 4, 5, 6, 7, 8, 11, 12), while dimension 2 (factor 2) was named "information technology" (items 9, 10). The EFA results showed that there were two dimensions in the ethical awareness scale, with the same 12 items as the ones used at the 
outset. No item was removed from the ethical awareness scale. The re-categorization from three factors to two factors was based on the contents of the item statements. The factors were different from the ones proposed in the blueprint. The academic and social factors were grouped into one factor, while information technology remained a separate factor. The total variance explained by the scale is $46.827 \%$, with factor 1 contributing to $39.001 \%$ and factor 2 contributing to $7.826 \%$ of the total variance.

\section{Reliability}

In addition to the validity of the ethical awareness scale, a reliability test was performed. The reliability of a scale indicates the consistency or accuracy of a measurement and construct measurement. The closer the reliability coefficient is to 1 , the more reliable is the scale (Azwar, 2017). The ethical awareness scale was found to have a Cronbach's Alpha coefficient of $\alpha=0.874$.

\section{Hypothetical Norms of the Ethical Awareness Scale}

The score obtained by each participant on the ethical awareness scale could then be organized into a classification system. According to (Azwar, 2017), a norming system based on the theoretical scores of the population is necessary, so that position in the population can be estimated. This ethical awareness scale has 12 items and the scoring range is $0-2$, yielding a maximum score of 24 and a minimum score of 0 . The hypothetical mean for the scale is $\mu=12$. Meanwhile, the hypothetical standard deviation showed $\mathrm{SD}=4$. A low category on ethical awareness implies that an individual lacks sensitivity in recognizing ethical issues, and vice versa. The hypothetical norm categorization of the ethical awareness scale is listed in Table 5.

Table 5. Hypothetical Norms of the Ethical Awareness Scale

\begin{tabular}{ccc}
\hline Category & Formula & Score \\
\hline Low & $\mathrm{X}<\mu-1 . \Sigma$ & $\mathrm{X}<8$ \\
Medium & $\mu-1 . \sigma \leq \mathrm{X}<\mu+1 . \Sigma$ & $8 \leq \mathrm{X}<16$ \\
High & $\mathrm{X} \geq \mu+1 . \Sigma$ & $\mathrm{X} \geq 16$ \\
\hline
\end{tabular}

Source: Personal Data (2019)

\section{Discussion}

The ethical awareness scale addressed in the current research is meant to be utilized for measuring one's sensitivity to recognize ethical issues in various situations and to compare such issues to the normative standards applicable to Indonesian university students. From an operational standpoint, the scale illustrates university students' perceptions on ethical issues, such that they are able to determine whether an issue is right or wrong, positive or negative, and appropriate or inappropriate. Moreover, philosophically, the scale is developed upon a specific utilitarianism viewpoint, namely consequentialism. According to Roby (2018), a fundamental view of utilitarianism is that prior to deciding on an action, an individual would weigh in on the consequences of the action, its benefits and disadvantages, as well as whether it is deemed positive or negative.

Assessment of ethical awareness is crucial, as ethical awareness is a vital precondition for decision making. This is consistent with the arguments made by Rest et al. (1999) and Treviño, den Nieuwenboer, and KishGephart (2014) that the predisposition to make ethical decisions can be investigated by first examining ethical awareness or ethical sensitivity. There are four components of rational deliberation that an individual goes through when making a decision, which according to Jones (1991) consist of: (1) ethical awareness/ethical sensitivity; (2) ethical judgement; (3) commitment to act; and (4) performance of ethical act. It should therefore be obvious that in decision making, ethical awareness is the beginning of the rational deliberation process. By understanding this process, an individual who possesses ethical awareness is then better at making deliberations, which subsequently enhances their urge to act that is manifested in more targeted actions. 
The format of the ethical awareness scale in the current study is similar to that constructed by Milliken, (2017) and Milliken, Ludlow, DeSanto-Madeya, and Grace (2018). Among the similarities are the fact that the forms are simple, with items that are relatively short, easy to respond to, and directly correspond to various activities in daily context. The chosen format is, in and of itself, an advantage, which is proven by how all of the constructed items were suitable for use in the final version of the scale. Milliken et al. (2018) validated their ethical awareness scale (EAS) based on the education and ethical codes of nurses. The scale addresses the comprehension of an ethical issue and its ethical consequences, and the scale was tested on nursing students as subjects. Using their instrument, ethical awareness is indicated by the ability to identify the ethical implications of nursing practices. Among nurses and nursing students, ethical awareness is pertinent to facilitate the needs of patients, yet the daily ethical issues surrounding the nursing profession seem to still be neglected by nurses in their practices. The instrument developed by Milliken et al. (2018) consists of 33 items that have been tested psychometrically using the Rasch model of item response. The results of their study demonstrated that the Ethical Awareness Scale (EAS) is a good, reliable, and valid measure of ethical awareness.

As previously mentioned, the ethical awareness scale of the current study was extracted into two factors using exploratory factor analysis. The first factor is the academic and social factor, while the second is information technology. Yeung and Keup (2009) defined the academic factor as all forms of activities related to university coursework, including attendance, article and report writing, and examinations. Whereas, the social factor refers to social and societal activities associated with the daily life of a university student, while the information technology factor consists of activities pertaining to the use of technology to facilitate the completion of coursework. In contrast to Yeung and Keup's (2009) study, the academic and social factors (dimensions) of the current research are combined into one factor. Meanwhile, the information technology factor, which was previously a part of the learning facilities factor, acts as a standalone factor in the current study.

Academic and social factors, as well as technology factors in ethical awareness were also addressed in a study by Iorga, Ciuhodaru, and Romedea (2013) on 369 Romanian students. As many as $70 \%$ of the study participants reported having committed academic violations like plagiarism, cheating, lying when submitting late assignments, and paying to obtain confidential examination documents. Other than academic factors, respondents also admitted to violating social rules, such as bribing academic staff to pass failed examinations. With regard to violations associated with the use of technology, participants reported having illegally accessed computer database and sabotaged other people's experiments. Iorga et al., (2013) study further highlights the need for ethical awareness that begins in the early years of formal education and should persist all through one's professional stage of life.

With regards to academic factor, Lin and Wen (2007)Lin and Wen conducted a study on 2068 university students in Taiwan in which they discovered that the most prevalent issues pertained to honesty or dishonesty in term examinations and assignment completions, as well as in activities related to academic documentation. The most frequent academic violations among the Taiwanese students were dishonesty in assignment completion and cheating. The findings were further supported by Dömeová and Jindrová (2013), who conducted research on students at the Faculty of Economics and Management, University of Life Sciences in Prague, and similarly found that cheating was the most common form of academic violation. Academic activities on university campuses are indeed distinct from those in secondary schools. As a consequence of this difference, students who experience academic troubles may resort to such shortcuts as cheating. Cheating is typically done due to difficulties in following course materials, time constraint during exam preparation, lack of interest in certain subjects, conformity to friends, having lecturers who are lenient in enforcing rules, and higher orientation towards scores than to processes.

Within the context of ethical awareness, academic factor is inseparable from social factor. This is demonstrated in a study by Cho and Hwang (2019) on 581 nursing students from three universities in South 
Korea. Academic ethical awareness is of great importance especially for nursing students who, in caring for patients, are expected to maintain patient confidentiality and to uphold honesty during examinations. This academic ethical awareness is also entwined to such social relations as respectful and courteous behaviors toward lecturers and friends. In other words, an individual who possesses courtesy and respect for others will tend to not disappoint others by avoiding performing acts that would put others at a disadvantage. There also exist differences in ethical awareness between genders and among different years of study. In particular, with regards to gender, male students showed a relatively higher ethical awareness compared to female students. Similarly, first year students also demonstrated a higher ethical awareness than end-year students.

The social factor of ethical awareness (i.e., social awareness) is described by Huynh (2018) as a combination of flexibility, change, and adaptation of an individual's behavior in a specific environment. Shrivastava (2016) added that social awareness also reflects the ability to understand and respond to the needs of other people, to comprehend emotions, to attend to and care for the needs of other people, as well as to understand a group and to influence the people within it. In the literature review conducted by Joshi, Srivastava, and Raychaudhuri (2012), social awareness is said to correlate with academic performance. Additionally, social awareness is an indicator of an individual's emotional intelligence. According to New and Ghafar (2012), while carrying the values and beliefs from their past, students attempt to adjust to a new environment in the university campus. In their research, an in-depth interview method was carried out on 15 university students aged 15-23 years in Malaysia. Awareness of social context was found to aid students in properly responding to their environment. Social environment appears to play a key role in selfdevelopment, as it enables students to become well-integrated members of society and to make real contributions in upholding public order.

In the current era, an information technology factor is taken into account when measuring students' ethical awareness due to the fact that the use of information technology implicates ethical concerns that need to be considered. Students are able to access technology with ease and often assuming that all downloadable contents belong to the public domain, when in fact, some contents are licensed and require purchases. In terms of information technology, Sherratt, Rogerson, and Fairweather (2005) emphasize the need to understand the rules that govern the downloading of articles and books, software downloads, access to computer database, and etiquettes and courtesy in online communication. Yet there is a lack of comprehension of such rules and etiquettes even among students majoring in information technology. A study by Masrom, Ismail, and Hussein (2009) found that there is a significant difference in ethical awareness among undergraduate students majoring in computer science in several universities in Malaysia. The study involving 159 university students, revealed that students from higher education institutions with religious affiliation (i.e., Islam) who teach courses on ethics generally displayed higher ethical awareness.

The present study has several limitations. First, the information technology factor included in the ethical awareness scale is comprised of only two items. Yet according to Costello and Osborne (2005), a good factor should consist of at least three items. The two items in the information technology factor were the result of factor rotation, and the factor was re-labeled after extraction from the original factor. The factor of origin did not only include indicators on information technology, but also contained items on campus facilities, including campus cleanliness and parking permits. In the final version of the scale, items related to campus facilities were reassigned to the academic and social factor. This limitation implies that the contribution of the information technology component is relatively weaker than the contribution of the academic and social component. Second, the results of the study were not followed by a subsequent confirmatory factor analysis to evaluate the CFA findings of the factor structure and psychometric properties of the measure. Third, testing of the scale was not accompanied by a social desirability check of the responses, suggesting that a response bias in the form of faking good behaviors may have possibly occurred. 


\section{Conclusion}

The ethical awareness scale constructed in the current study has a high item discrimination power in its statement items which is reflected in the corrected item-total correlation range of 0.473-0.686 (above the critical value of 0.3 ). Exploratory Factor Analysis yielded a KMO Bartlett value of 0.865 (>0.05), df =66, $\mathrm{p}=$ 0.000 (significant). After EFA, the number of items remained constant at 12 items, with an extracted number of factors at two factors from the original three factors. The factor loading range is 0.409-0.814. All items in the ethical awareness scale showed eugine values factor with a factor loading of above 0.4. Furthermore, dimension 1 (factor 1) was renamed as academic and social, while dimension 2 (factor 2) was renamed as information technology. The total variance explained in the scale is $46.827 \%$, with factor 1 contributing to $39.001 \%$ and factor 2 contributing to $7,826 \%$ of total variance. The scale has an Alpha Cronbach reliability coefficient of $\alpha=0.874$. In conclusion, the item discrimination power, construct validity, and reliability of the ethical awareness scale are all sufficient.

The implications of the study include the need for further development of the measuring instrument, specifically the means of improving the information technology factor through the addition of indicators and the number of items to the factor, a follow up confirmatory factor analysis to ensure applicability of the scale to other students, and a modification of the scale to be used with other respondent populations. Social desirability should also ideally be addressed using such instruments as the Marlowe Crowne Scale. Furthermore, the practical implication of the current research suggests that the constructed ethical awareness scale can be used to reveal the effectiveness of ethics outreach programs for university students.

\section{References}

Azwar, S. (2017). Penyusunan skala psikologi (kedua). Yogyakarta: Pustaka Pelajar.

Bairaktarova, D., \& Woodcock, A. (2017). Engineering student's ethical awareness and behavior: a new motivational model. Science and Engineering Ethics, 23(4), 1129-1157. https://doi.org/10.1007/s11948-016-9814-X.

Cho, O. H., \& Hwang, K. H. (2019). Academic ethical awareness among undergraduate nursing students. Nursing Ethics, 26(3), 833-844. https://doi.org/10.1177/0969733017727155.

Costello, A. B., \& Osborne, J. W. (2005). Best practices in exploratory factor analysis: Four recommendations for getting the most from your analysis. Pracctical Assestment, Research \& Evaluation, 10(7), 1-9.

Dömeová, L., \& Jindrová, A. (2013). Unethical behavior of the students of the Czech university of life sciences. International Education Studies, 6(11), 77-85. https://doi.org/10.5539/ies.v6n11p77.

Donaldson, T., \& Dunfee, T. W. (2017). Toward a unified conception of business ethics: Integrative social contracts theory. In Corporate Social Responsibility. https://doi.org/10.2307/258705.

Fabrigar, L. R., MacCallum, R. C., Wegener, D. T., \& Strahan, E. J. (1999). Evaluating the use of exploratory factor analysis in psychological research. Psychological Methods, 4(3), 272-299. https://doi.org/10.1037/1082-989X.4.3.272.

Gholami, K., \& Tirri, K. (2012). The cultural dependence of the ethical sensitivity scale questionnaire: The case of Iranian Kurdish teachers. Education Research International. https://doi.org/10.1155/2012/387027.

Howard Buchan. (2014). Reidenbach and Robin's multidimensional ethics scale: testing a second-order factor model. Journal of Psychology Research, 4(10), 823-834. https://doi.org/10.17265/2159$5542 / 2014.10 .007$.

Hurlock, E. (2006). Psikologi perkembangan Jakarta. Jakarta: Erlangga.

Huynh, V. (2018). Social awareness and responsible decision making of student in grade 4 and 5 in Vietnam. 
Journal of Education and Human Development, 7(4), 7-15. https://doi.org/10.15640/jehd.v7n4a1.

Iorga, M., Ciuhodaru, T., \& Romedea, S.-N. (2013). Ethic and unethic. Students and the unethical behavior during academic years. Procedia - Social and Behavioral Sciences, 93, 54-58. https://doi.org/10.1016/j.sbspro.2013.09.151.

Jones, T. M. (1991). Ethical decision making by individuals in organizations: an issue-contingent model author ( s ): Thomas M . Jones Source: The Academy of Management Review , Apr ., 1991, Vol . 16 , No . 2 ( Apr ., 1991 ), Published by: Academy of Management Stable URL, 16(2), 366-395.

Joshi, S. V., Srivastava, K., \& Raychaudhuri, A. (2012). A descriptive study of emotional intelligence and academic performance of MBBS students. Procedia - Social and Behavioral Sciences, 69(Iceepsy), 20612067. https://doi.org/10.1016/j.sbspro.2012.12.165.

Lin, C. H. S., \& Wen, L. Y. M. (2007). Academic dishonesty in higher education-a nationwide study in Taiwan. Higher Education, 54(1), 85-97. https://doi.org/10.1007/s10734-006-9047-z.

Martinov-Bennie, N., \& Mladenovic, R. (2015). Investigation of the impact of an ethical framework and an integrated ethics education on accounting students' ethical sensitivity and judgment. Journal of Business Ethics, 127(1), 189-203. https://doi.org/10.1007/s10551-013-2007-5.

Masrom, M., Ismail, Z., \& Hussein, R. (2009). Ethical awareness of computer use among undergraduate students. ACM SIGCAS Computers and Society, 39(1), 27-40. https://doi.org/10.1145/1565795.1565798.

Milliken, A. (2017). The development and psychometric validation of the ethical awareness scale. Dissertation. Retrieved from Boston College William Connell school of Nursing

New, K. H., \& Ghafar, M. N. A. (2012). Self-awareness and Social change in higher education. World Journal of Education, 2(1), 25-38. https://doi.org/10.5430/wje.v2n1p25

Nguyen, C.P. (2010). Author guidelines for reporting scale development and validation results in the Journal of the Society for Social Work and Research . Journal of the Society for Social Work and Research, 1(2), 99-103. https://doi.org/10.5243/jsswr.2010.8.

Reio, T. G., \& Shuck, B. (2015). Exploratory factor analysis: implications for theory, research, and practice. Advances in Developing Human Resources, 17(1), 12-25. https://doi.org/10.1177/1523422314559804.

Rest, J. R., Narvaez, D., Thoma, S. J., \& Bebeau, M. J. (2000). A Neo-Kohlbergian approach to morality research. Journal of Moral Education, 29(4). https://doi.org/10.1080/713679390.

Roby, B. (2018). Virtue ethics, deontology, and consequentialism. Retrieved from https://scholar.umw.edu/cgi/viewcontent.cgi?article=1278\&context=student_research.

Shawver, T. J., \& Sennetti, J. T. (2019). Measuring ethical sensitivity and evaluation linked references are available on JSTOR for this article: measuring ethical sensitivity and evaluation, 88(4), 663-678. https://doi.org/10.1007/s10551-008-9973-z.

Sherratt, D., Rogerson, S., \& Fairweather, N. Ben. (2005). The challenge of raising ethical awareness: A case-based aiding system for use by computing and ICT students. Science and Engineering Ethics, 11(2), 299-315. https://doi.org/10.1007/s11948-005-0047-7.

Shrivastava, S. K. (2016). Role of educational institusions in promoting social awareness. Journal of Innovative REsearch and Advanced Studies, 3(13), 24-26.

Treviño, L. K., den Nieuwenboer, N. A., \& Kish-Gephart, J. J. (2014). (Un)ethical behavior in organizations. Annual Review of Psychology, 65(1), 635-660. https://doi.org/10.1146/annurev-psych113011-143745.

Yeung, F. P. F., \& Keup, J. R. (2009). Ethical decision-making in college: choosing between right , wrong, and the space in between. University of California Berkeley: Research \& Occasional Papaer Series: CSHE.2.09. Retrieved from http://chse.berkeley.edu/. 